Lola Caparrós Masegosa, Historia y crítica de las exposiciones nacionales de bellas artes (1901-1915), Universidad de Granada, 2014, 533 páginas.

\title{
UN LIBRO DE REFERENCIA PARA LA HISTORIA DEL ARTE ESPAÑOL DE LAS DOS PRIMERAS DÉCADAS DEL SIGLO XX
}

\author{
Ana María Fernández García* \\ Universidad de Oviedo
}

Hasta la fecha, la historia de las exposiciones nacionales de Bellas Artes creadas a partir del Real Decreto de 1853 tenía dos lecturas básicas y complementarias: el clásico trabajo de Bernardino de Pantorba que desde 1948 ha sido una referencia obligada en los estudios de pintura española, y el más reciente trabajo de Gutiérrez Burón en 1987. Pero a todas luces estos trabajos generalistas debían tener el contrapunto en análisis más pormenorizados como el que la profesora Lola Caparrós ha abordado para deleite de los especialistas.

El trabajo se centra en las exposiciones nacionales de Bellas Artes que tuvieron lugar entre 1901 y 1915, recogiendo siete muestras que se han estudiado de una manera exhaustiva, pormenorizando todos los detalles de sus reglamentos, limitaciones o plazos, los jurados y sus desencuentros, la situación y colocación de la obras o los protocolos de inauguración, así como los premios y valoración crítica de los certámenes. La elección de este marco cronológico no es casual. Responde a un momento de inflexión entre los modos académicos heredados del ochocientos enraizados en España en las exposiciones nacionales de Bellas Artes y su ocaso como vehículo de promoción a partir de 1917. Son además los años decisivos de llegada de nuevas corrientes estéticas y de fructíferos debates sobre el rol del campo artístico y sus ulteriores complejidades.

Las siete muestras recogidas en las más de quinientas páginas del ensayo son un verdadero alarde de erudición y documentación. Se han trabajado de manera rigurosa y metódica los fondos del Archivo General de la Administración contrastando los documentos con la abundante crítica del momento, recogida en las principales publicaciones periódicas nacionales. Con esos mimbres el resultado no podía decepcionar a nadie. En sus páginas se abordan aspectos 
fundamentales para entender las artes de las dos primeras décadas del siglo XX y su oficialización a través de las muestras oficiales. En el primer capítulo se ofrece un esclarecedor análisis de su idiosincrasia organizativa, los cambios de reglamentación originados por polémicas e ideas encontradas y el funcionamiento de la "sala del crimen", donde se exhibían cuadros digamos heterodoxos, como los de Regoyos, Sola o Nonell, tildados a veces de "engendros". En el capítulo segundo la autora encara un estudio tenaz e inteligente de la fortuna crítica de las exposiciones nacionales. En él se subrayan aspectos muy interesantes para la historiografía nacional, como las condiciones que debía tener un crítico de arte, la vertiente didáctica de las muestras y la plasmación de algunos impulsos ideológicos inherentes como el nacionalismo, la llegada de nuevas ideas estéticas o la opinión de algunos teóricos del momento sobre los certámenes como un elemento de aglutinación social, de cierta democratización progresista.

Los siete capítulos restantes analizan individualmente cada exposición, desde la de 1901 en homenaje a Sorolla hasta la de 1915. Para homogeneizar el discurso, la autora ha optado por una taxonomía clara en cada apartado, abordando cada historia expositiva desde el origen (con los reglamentos), la elección de los jurados, los problemas de admisión con los consecuentes rechazos por la calidad, novedad o amoralidad supuesta de las obras, la organización de los eventos y su inauguración, para acabar en cada caso con los premios y sus respectivas polémicas y un catálogo obras acompañado por la opinión de la crítica. La organización de la información es, por tanto, impecable. Facilita la lectura y consulta de la ingente información recogida y permite -con sus digresiones y comparaciones- comprender el rico trasfondo histórico de una época, hilvanado con problemas personales, ideas confrontadas y con la realidad de una variada actividad creativa nacional. Hay que hacer notar los debates aportados sobre el rol de las artes decorativas en el seno de tales certámenes, que culminarán en su separación definitiva de las bellas artes a partir de 1910, para celebrarse en años alternos aunque compartiendo muchos de los principios regulatorios y organizativos.

El libro de Lola Caparrós es, en definitiva, un estudio erudito, enriquecido con unos interesantes anexos de ilustraciones, catálogos detallados y documentos inéditos. Si durante años el clásico libro de Bernardino de Pantorba estaba en las mesas de todos los investigadores de las artes españolas contemporáneas, a partir de ahora La historia y crítica de las exposiciones nacionales de Bellas Artes (1901-1915) se añadirá al paquete básico de cualquier erudito, a la biblioteca de todos los estudiosos de un periodo que no deja, como bien demuestra este tomo con formato de tesis doctoral, de abrir nuevas vías interpretativas y nuevas formas de conocer nuestro pasado artístico.

Fecha de recepción: 30 de diciembre de 2014

Fecha de revisión: 17 de enero de 2015

Fecha de aceptación: 15 de febrero de 2015 